This is a pre-print. Please cite the final version published in Journal of Moral Philosophy, 13(6), 2016, 699-719. doi: https://doi.org/10.1163/17455243-01306002

\title{
Moral Blackmail and the Family
}

Simon Keller, Victoria University of Wellington

\section{Some cases}

Your elderly father is booked for a medical procedure and will need to spend a day at the hospital. Your sister does the bulk of the caring for your father, but this time you have agreed to drive him to hospital and keep him company for the day. You would never want your father to miss the procedure, but you wish that you did not have to take him - for no other reason than that you would prefer to have the time to yourself. So you come up with a plan that will let you get all you want. Early on the morning of the procedure, you text your sister to say that you will not be collecting your father after all, and then you turn off your phone, making yourself impossible to contact. Given the situation in which you have placed her, you are sure your sister will cancel her other plans and take your father to the hospital herself. The alternative, after all, would be to allow your father to miss his needed medical procedure.

Confident that your father will have the procedure without your having to take him, you go off and enjoy your day.

A colleague comes into your office, wanting to chat, just as you are leaving to collect your child from daycare. You know that if you stay to chat then you will not arrive at the daycare center until after its closing time. But you judge that if you are not at the daycare center right when it is supposed to close, the teacher will surely stay late to look after your child. What sort of teacher, after all, would be so irresponsible 
as to leave a small child unattended? Comforted by that thought, you enjoy a chat with your colleague.

As a school principal, you are trying to raise money to build a new

playground. A local business owner has agreed to make a donation that will cover half the cost, but you still need to find the rest of the money. So you make a plan. You invite the business owner to a school assembly, and, with the children and teachers present and to rapturous applause, you announce that the business owner will be providing the entire cost of the playground. Then you invite her to the stage to say a few words. Having placed her in this position, facing a delighted and expectant audience, you figure that the business owner is likely to double her donation. To fail to do so, in the circumstances in which you have placed her, would create too much disappointment among the innocent teachers and children.

\section{This paper}

In each of the above cases, you pursue a goal by deliberately putting someone into an awkward position, making it difficult for her to perform any act other than the one you want her to perform. If she does not do what you want her to do, then she will leave her father unable to have the medical procedure he needs, or she will abandon a small child, or she will disappoint a group of innocent teachers and children. In manipulating her circumstances, you deny her the chance to make her own decision under fair conditions. She is likely to feel cornered and to feel exploited; she may feel as though she has been blackmailed.

The cases exhibit a kind of manipulation that I will call "moral blackmail." To commit moral blackmail is to change a person's situation so as to make it wrong for her to fail to do what you want her to do; it is to try to make her do something by 
making the alternatives morally unacceptable. ${ }^{1}$ Moral blackmail, I want to show, is a real and powerful phenomenon. It can be found in many areas of social life and has particular significance for our intimate personal relationships. My first goal in this paper is to say what moral blackmail is. Moral blackmail is not ordinary blackmail, but it is similar to ordinary blackmail in important respects, and I try to get clearer about the nature of moral blackmail by comparing it to ordinary blackmail and some of its variants. Later in the paper, I try to demonstrate the significance of moral blackmail by exploring some of its appearances in one central realm of social life: the family. I aim to show that an understanding of moral blackmail yields insights into the power dynamics that operate between family members, the morality of laws and public policies that place responsibility for the care of vulnerable people first upon their families, and the moral consequences of traditional gender roles assigned within the family.

\section{Blackmail}

In a paradigm case of blackmail, I might come across some embarrassing personal information about you and threaten to make it public unless you pay me some money. Or I might discover that you are engaging in a criminal activity and

\footnotetext{
${ }^{1}$ Terrence C. McConnell uses the term "moral blackmail" to describe a narrower phenomenon than the one I explore here. See 'Moral Blackmail' Ethics 91:4 (1981): 544-567. For McConnell, moral blackmail involves an agent threatening to do some evil thing unless a second agent does some less evil thing (pp. 554-555). For example, a tyrannical dictator demands that we hand over a small number of dissidents who have fled to our country, or else he will torture a large number of members of our diplomatic staff in his country (p. 545). In McConnell's cases, as in mine, the blackmailer tries to make his victim do something by making her alternatives morally unacceptable; all of McConnell's cases fit within my conception of moral blackmail. Most of my cases of moral blackmail, however, do not fit within McConnell's conception; I do not require that the blackmailer threatens to do something evil, and I do not require that the act the blackmailer wants his victim to perform is morally wrongful.
} 
threaten to go to the authorities if you do not you buy my silence. This is the kind of conduct that is most likely to constitute the crime of "blackmail" as defined under the law. $^{2}$

From the blackmailer's perspective, the point of an act of blackmail is to cause someone to perform a certain act by making her other options unacceptable. As a blackmailer, there is something I want you to do: to give me money, perhaps. To make you do what I want you to do, I try to make it the case that doing it is in your best interests, in the circumstances in which you find yourself; I might ensure that if you do not give me the money then some damaging information about you will be revealed. For my act of blackmail to succeed, I need to set the incentives correctly, so that you really will suffer a lesser harm by submitting to my threat. If I demand too much money or if the information I threaten to release is not sufficiently damaging, then you might rationally choose not to submit to my threat, leaving me still without the money I want.

Blackmail involves more, however, than just trying to make someone do something by making her alternatives unacceptable. Think about a normal retail transaction. As a retailer, I want your money, so I put a price on a product you want. My intention is to place you in a situation under which it is worse for you to keep your money and leave me holding the product than to give me the money and receive the product in return, and my plan fails if I do not set the incentives correctly. I may even put the deal in the form of a threat: if you do not give me the money, then you

\footnotetext{
${ }^{2}$ One typical definition, provided by the Legal Information Institute based in the Cornell University Law School, says that blackmail is "coercion by unjustifiably threatening to reveal to another person or to the public substantially true information that is embarrassing, injurious, or incriminating."

[https://www.law.cornell.edu/wex/blackmail] Accessed 29 Dec 2015.
} 
will not get the product. But in the case of the normal retail transaction, I do not do anything wrong and I am not guilty of blackmail.

The reason why I am not guilty of blackmail in the case of the ordinary retail transaction is, indeed, that in offering you the deal I do not do anything wrong. To commit blackmail, I need to make not just any threat, but a wrongful threat: a threat that is unwarranted or unjustified or exploitative, or is for some other reason a threat I am not entitled to make. This is part of the test for blackmail under the law. ${ }^{3}$ It is essential to the paradigm cases of blackmail that I have no right to demand money for keeping the embarrassing information about you secret, and that it is wrong for me to demand money for keeping quiet about your criminal activity. I am not guilty of blackmail in the case of the ordinary retail transaction because I have every right to put a price on my product.

"Blackmail," then, is a moral concept. To describe an act as "blackmail" is to say, in part, that it is in some respect wrongful. "Blackmail" is a moral concept in the same sense in which "murder" is a moral concept. We can see that a given act is a killing, but whether we regard it also as a murder depends partly on whether we think it is a wrongful killing. A result is that people with different opinions about what killings are wrongful can disagree about whether a particular killing counts as a murder. Analogously, where people have different opinions about what demands can legitimately be made under what circumstances, they can disagree about whether a particular act counts as blackmail.

\footnotetext{
${ }^{3}$ In the United Kingdom, the crime of blackmail is defined in section 21 of the Theft Act 1968. It begins: "A person is guilty of blackmail if, with a view to gain for himself or another or with intent to cause loss to another, he makes any unwarranted demand with menaces" (my emphasis). The Legal Information Institute's definition, as cited in the previous footnote, says that blackmail is "coercion by unjustifiably threatening to reveal..." (my emphasis).
} 
Beyond the paradigmatic cases of criminal blackmail, there are cases in which a person uses just the same strategy as the criminal blackmailer, and does something morally wrong, but does not do anything that would be actionable under the law. I might tell you that if you do not help me with my homework then I will tell everyone at school that you wet the bed. Or I might tell you that if you do not drive my child to soccer practice then I will tell your husband that you were out having fun when you said you were working late. Whether or not we would ordinarily describe these as cases of "blackmail," from an ethical point of view they display all of blackmail's significant features. I make a morally wrongful threat, trying to make you do something by making your other options unacceptable.

Moving a further step away from the paradigmatic cases of blackmail, there are cases that look much like blackmail, and involve the same basic form of manipulation, but do not involve an explicit threat. When you refuse to buy me an ice cream, I might begin to scream at you in front of everyone in the store, making it clear that the tantrum will continue until the ice cream arrives. The absence of a stated threat in this case is unlikely to prevent you from feeling that I am trying to corner and exploit you. I have not made an explicit threat, but for all the difference it would make, I may as well have.

Then there are cases that do not involve threats, explicit or implicit, but exhibit much the same form of manipulation. Suppose that you and I go out to dinner together and I deliberately fail to bring my wallet, motivated by the thought that if I do not have any way of paying then you will pay for both of us. Once you realize that I do not have my wallet, I figure, you will judge that the most convenient option available is to pay the whole bill yourself; it will be less of a hassle to pay the whole bill than to insist to the waiter that you are only paying half and he will need to chase 
me for the rest. In this case, I do not subject you to a threat, but I nevertheless try to manipulate your circumstances so as to make you do what I want you to do, by leaving your other options unacceptable. I engage in deliberate and wrongful manipulation, and I deprive you of the chance to make your own decision under fair conditions. You are likely to feel the indignation felt by a victim of blackmail: the indignation of being cornered and exploited. It may or may not be natural to describe my act in this case as one of "blackmail," but I do employ the blackmailer's basic strategy.

In the paradigmatic cases of blackmail and in the variants just offered, I try to manipulate your behavior by leaving you with a choice between greater and lesser harms to yourself. My plan is to leave you with prudential reason to give me what I want: better for you to give me what I want than to have embarrassing or damaging information revealed, or to be subjected to a public tantrum, or to face an awkward situation with a waiter. I set out to change your behavior by manipulating the facts about your self-interest. Blackmail of this kind, we can say, is "prudential blackmail."

\section{Emotional blackmail}

The blackmailer's basic strategy can be also be used to manipulate the facts about a person's emotions, as distinct from the facts about her self-interest. I do not want a dog, and my reasons for not wanting a dog, I think, are pretty good. At this point in my life, taking responsibility for a dog would make my life worse. Still, if you wanted me to take ownership of a dog, you could probably achieve your goal by using the right strategy. You could introduce me to a puppy and let me play with it and get to know it. Then, once you see that I have formed a bond with the puppy, you could seize your moment: you could inform me that the puppy is due to be put down 
because nobody wants it. I would be very likely to agree to take the dog home and make it mine. You can predict that I will not have the heart to leave the puppy to be killed.

While agreeing to take ownership of the dog, I might stand by my judgment that it is better for me not to own a dog and that I will be worse off if I take ownership of this one. I may also be aware that you have manipulated my circumstances to achieve your end, and I may feel that I have been exploited and that you have acted wrongly in taking advantage of me. Still, I may find myself unable to refuse to take ownership of the puppy. My problem is that I have fallen in love with the puppy. Your strategy succeeds by manipulating my emotions. My only emotionally acceptable option is to do what you want me to do.

"Emotional blackmail" has a meaning in psychotherapy. ${ }^{4}$ It also has a colloquial meaning, though one that is difficult to pin down. ${ }^{5}$ For present purposes, a convenient way of understanding emotional blackmail is as involving the use of the blackmailer's basic strategy to achieve a goal by manipulating another person's emotions. You try to make someone do something not by making her other options prudentially unacceptable, but by making them emotionally unacceptable. Emotional blackmail, so understood, can involve manipulating another person's affections, or,

\footnotetext{
${ }^{4}$ On "emotional blackmail" as used in psychotherapy, see Susan Forward, Emotional Blackmail (New York: HarperCollins, 1997). Forward describes a pattern of interactions within relationships in which one person tries to get the other person to perform certain acts or have certain feelings by manipulating the other's feelings of fear, obligation, or guilt. Some of Forward's cases of manipulation through feelings of obligation and guilt are similar to my cases of moral blackmail; see, for example, the case of Lynn and Jeff on p. 52.

${ }^{5}$ In everyday conversation and in news articles and elsewhere, the term "emotional blackmail" is used to denote many, many different forms of manipulation. The only points of general agreement, I think, are that emotional blackmail involves appealing to another person's emotions as distinct from her better judgment, and that emotional blackmail, whatever it is, is wrong.
} 
among other things, taking advantage of her fears, or her grief, or her feelings of guilt or shame.

\section{Moral blackmail}

The three cases with which I began this paper - leaving your sister take your father to hospital, staying to chat with your colleague confident that the daycare teacher will stay late, and trying to make the business owner double her donation - all involve the form of manipulation that I have called "the blackmailer's basic strategy." They share something with the paradigmatic cases of blackmail and their variants, and they share something with emotional blackmail (as I have described it). But they are different from those kinds of blackmail too. They involve the manipulation of the victims' moral situations.

When you tell your sister that you will not be taking your father to the hospital, you deliberately place her in a situation under which it is difficult for her to do anything other than what you want her to do. Even while facing that situation, however, she may judge that it is in her best interests to stick with her plans and let your father miss the procedure, and her emotions may incline her to refuse to take your father to the hospital too. Perhaps looking forward to having some time to herself, weary at the thought of a long day with your father at the hospital, and resentful at your maneuvering, she might find it emotionally easier, on the whole, to let your father miss the procedure and force you to face the consequences. What might stop her from making that decision is the thought that your father would then miss the medical procedure, which he needs. Her motivating thought might be about the interests of your father, or about her filial duty. She might feel forced to take your father to the hospital not because she will then be better off, or because that is the way 
in which she is emotionally inclined, but because otherwise she would do something wrong. If that is the situation into which you intend to place your sister, then your plan depends upon manipulating her moral predicament, not her self-interest or her emotions.

Similarly, when you try to make the daycare teacher stay late and when you try to make the business owner double her donation, facts about their self-interest and emotions may or may not incline them to do what you want them to do. Your real power and their real weakness come from facts about morality. It would just be wrong of the teacher to leave a child unattended, even if that is exactly what she feels like doing. There is a moral reason for the business owner not to disappoint the teachers and children, even if that is something she is quite emotionally capable of doing. You manipulate your victims by changing their circumstances so that they face moral demands they would otherwise avoid. You try to make them do what you want them to do by making the alternatives morally unacceptable.

\section{Morality against morality}

If there is really such a thing as moral blackmail, then it must be possible for me wrongly to place you in a situation under which you are morally required to do what I want you to do. There is something uncomfortable, perhaps paradoxical, about that possibility. There is at any rate a difference here between moral blackmail and ordinary blackmail.

In a case of ordinary blackmail, the blackmailer makes a wrongful demand, and so - it is plausible to think - the intended victim has no obligation to accede to that demand. When I threaten to release the damaging information unless you pay, you might resolve not to submit to blackmail. You might stand on principle, keep 
your money, and let me do my worst. You would then, by hypothesis, choose to suffer a greater harm, but you may nevertheless feel that you act within your moral rights. You stand up for yourself; you refuse to be bullied; you show that you will not be pushed around by the likes of me. Rejecting my threat may be imprudent, but it does not appear to be immoral. And that, arguably, reveals something about the very concept of blackmail. To commit blackmail, perhaps, is to put pressure on someone to do something - like giving you money - that she has every right not to do.

As a victim of moral blackmail, in contrast, you cannot feel morally justified in refusing to do what the blackmailer wants you to do. That is the point. Think of it from the perspective of your sister, forced to choose whether or not to take your father to the hospital. She might feel inclined to let your father miss his medical procedure, just to show that she will not bow to pressure. She may even feel that in refusing to change her plans and refusing to take your father to the hospital, she stands up for herself. If she has genuinely been morally blackmailed, however, then it would be wrong for her to fail to take your father to the hospital. When a victim of moral blackmail refuses to act as the blackmailer wants her to act, she does not thereby stand on principle: not on moral principle, anyway.

This difference between moral blackmail and ordinary blackmail marks the respect in which moral blackmail turns morality against itself. As a victim of moral blackmail, you find yourself directed by morality to accede to the wishes of your blackmailer. As a result of the blackmailer's acting wrongly towards you, you have moral reason to give her what she wants. It is as though morality rewards the blackmailer for his immoral action. It might reasonably be wondered whether this makes any sense. Is it really possible for morality to be turned against itself in such a fashion? If so, how does it happen? 


\section{Moral rights and moral reasons}

Here is one tempting story - though one that I think ultimately fails - about how moral blackmail turns morality against itself. Sometimes you have the right to do something, even though it would be indecent of you to exercise that right. ${ }^{6}$ You can have a moral right to do something while having moral reason not to do it. That is one respect, perhaps, in which morality can turn against itself, and perhaps it reveals something about what goes on in cases of moral blackmail.

When you are blackmailed, we could say, you are placed in a situation under which you have moral reason not to do what you yet have the moral right to do. Perhaps it would be good of your sister to take your father to the hospital, now that you have absconded, and perhaps it would reflect badly on her character if she chose to let your father miss the procedure he needs. But still, we might say, she has no duty to take your father to the hospital, since it was agreed that the job was yours; we would then maintain that she has the right to refuse to take him to the hospital. Her being morally blackmailed might involve her being placed in a situation under which she has good moral reasons, to do with her father's interests, not to exercise her moral right to have the day to herself, as promised. Moral blackmail in general, on this suggestion, involves raising the moral cost of the victim's insisting on her moral rights. As a moral blackmailer, runs the story, I give you moral reasons to do what I want you to do, without taking away your moral right to do otherwise.

The reason why this story is unconvincing, in my view, is that there are cases in which moral blackmail goes so far as to make it morally impermissible for the

\footnotetext{
${ }^{6}$ Judith Jarvis Thomson makes use of the distinction between reasons of decency and moral rights in 'A Defense of Abortion,' Philosophy and Public Affairs 1:1 (1971) 47-66, especially pp. 59-62.
} 
victim to do anything other than what the blackmailer wants her to do. A victim of moral blackmail can truly be left with the moral duty to act as the blackmailer wishes, and without the moral right to do anything else. To find such cases, we just need to raise the stakes. If it is vitally important that your father have this medical procedure on this day - if his life depends on it and there is no possibility of his having it later then your sister's duty to your father demands that she take him in for the procedure, now that you have left her as his only hope. It may be your fault that she is burdened with that duty, but it is her duty nonetheless. The daycare teacher who is left with an uncollected child at closing time would not be within her moral rights (forget about her legal rights) to leave the child there alone; you just do not do that to a small child. With the right measures of planning and malicious intent, you can perform a wrongful act that leaves someone with a moral duty, not just a moral reason, to do what you want her to do. You can ensure that she has no right to do anything else. We cannot presume that the victim of moral blackmail retains the right not to submit to blackmail.

\section{Moral situations, and the correct account of moral blackmail}

Towards constructing a different explanation of moral blackmail - the explanation I think is correct - I want to begin with the idea of a "moral situation." Your moral situation is constituted by the particular moral rights, duties, permissions, and reasons that you have, in your particular circumstances. Perhaps you have promised to meet me for coffee. If so, then one constituent of your present moral situation, all else equal, is a moral obligation to meet me for coffee. Like everyone else, you have a general moral obligation to keep your promises, and as a result of 
your making this promise, your moral situation now includes the particular obligation to meet me for coffee.

Moral situations are themselves up for moral evaluation. I can coherently say, for example, that it is unjust that I have certain moral duties, or that it is unfair that I am burdened with moral obligations that others do not share. As one possible example, it can be a matter of luck that my father is sickly and needy while your father is healthy and independent, and as a result that I need to make sacrifices for my father that you do not need to make for yours; in such a case I might accept that you and I have different obligations to our respective fathers, but also complain that this is unjust. As another possible example, I might happen upon the scene of a house fire and be required to endure minor burns so that I can help the occupants of the house escape, while you might be lucky enough never to need to endure minor burns in order to do the right thing; and this difference between our respective moral circumstances, perhaps, could be seen as unfair.

Putting it another way, it is possible for the burdens of morality to fall more heavily on some than on others, for no good moral reason. ${ }^{7}$ Where it is unjust that a person is in a moral situation, we can coherently say that there is a difference between the moral situation she is actually in and the moral situation she should be in. She can genuinely have certain moral duties, permissions, rights, and reasons, even though, morally, she should not have them.

\footnotetext{
${ }^{7}$ In discussing the ethics of abortion, Rosalind Hursthouse considers the possibility that "nature bears harder on women than it does on men." The suggestion is that the different roles played by men and women in the reproductive process leave them facing different moral burdens and decisions; the decision about whether to have an abortion, for example, could be seen as a demanding ethical decision that is properly the woman's to make. Hursthouse, 'Virtue Theory and Abortion' Philosophy \& Public Affairs 20:3 (1991): 223-246; see p. 243.
} 
My suggestion is that in a case of moral blackmail, the blackmailer wrongfully manipulates the moral situation of the victim, placing the victim into a moral situation that she (morally) should not be in, and giving the victim moral obligations that she (morally) should not have. The complaint of the victim of moral blackmail is that she has deliberately been made subject to moral standards to which she should not be subject. The power of the moral blackmailer comes from his ability to manipulate the moral situation of his victim, changing her circumstances so that she falls under moral obligations that point her towards the act that he wants her to perform. Such manipulation can be wrongful and exploitative, even as it succeeds.

I think that the correct story to tell about your manipulation of your sister, when you try to make her take your father to the hospital, is this. Considering her history of putting more effort into caring for your father, and considering the promise you have made her, it would be unfair for her to be burdened with the moral obligation to take your father to the hospital. Nevertheless, as a result of your maneuvering, she is left with that obligation. Her moral situation genuinely and unequivocally includes an obligation to take your father to the hospital, but still, her having that obligation is unjust, and it was wrong of you to put her in this moral situation. There is something she must do, even though it is unjust that she must do it. That is the real respect in which moral blackmail turns morality against itself.

Prudential blackmail involves the morally wrongful manipulation of a person's prudential situation, emotional blackmail involves the morally wrongful manipulation of a person's emotional situation, and moral blackmail involves the morally wrongful manipulation of a person's moral situation. The morality of moral blackmail is accordingly more complicated than the morality of prudential blackmail and emotional blackmail. That explains why moral blackmail is different from other 
kinds of blackmail, and it explains how moral blackmail pits morality against morality. But it also shows how moral blackmail is possible, and what moral blackmail is. The idea of moral blackmail is intricate but coherent.

\section{Moral facts and moral beliefs}

In all the cases of moral blackmail I have offered, the blackmailer's strategy depends upon the victim's having a certain moral sensibility. Strictly speaking, successful moral blackmail depends on manipulation not of the moral standards to which the victim is subject, but rather the moral standards to which she believes she is subject. ${ }^{8}$ It also depends upon the victim's being motivated by her moral beliefs. When you decide to stay late and chat with your colleague, for example, your plan will fail if your child has a teacher who does not believe that it would be wrong to leave your child unattended, or a teacher who thinks it would be wrong but does not care.

Conversely, moral blackmail can succeed when you leave someone believing that she is morally required to perform the act you want her to perform, even if her belief is false. Suppose that you believe that it is sinful to shove an Australian. I could take advantage of your moral belief by putting you into a situation under which the only way for you to avoid shoving an Australian is to (say) give me some money. Perhaps I, an Australian, find you in a room with only one door, and I stand in the doorway blocking your path until you give me my money. My strategy could be

\footnotetext{
${ }^{8}$ I talk freely of moral "beliefs," but I do not mean to take a stand on the question of whether the attitudes in question are truly beliefs, or instead desires or expressions of approval or something else. Whatever attitude is involved in taking something to be right or wrong, that is the attitude through which the victim of moral blackmail is manipulated.
} 
perfectly successful, even if your belief is wrong and shoving Australians is not sinful at all.

While moral blackmail involves taking advantage of moral beliefs, rather than moral facts directly, that does not reveal anything special about moral blackmail. An analogous point applies to ordinary blackmail. When I threaten to release the damaging information about you unless you pay, my attempt at blackmail will fail if you do not believe that it is in your best interests to pay me rather than having the information released; if you think that you are better off keeping your money, then I will not get what I want, even if you are wrong about your own interests. And my attempt to blackmail you will also fail if you believe that you will be better off if you pay me, but you do not care; perhaps you care more about resisting my manipulations than you do about protecting your own interests. Furthermore, I can successfully blackmail you if I leave you believing that you will suffer the lesser harm by doing what I want you to do, even if in fact you would not; perhaps the release of the information will not really be damaging, but if you believe that it will be, then that could be enough to make you choose to give me the money.

In one sense, this is to say, all blackmail works through the manipulation of the victim's states of mind: her beliefs, goals, fears, motives, and concerns. A blackmailer manipulates her victim's states of mind by manipulating her circumstances, leaving her in a situation under which only one course of action is acceptable to her, according to her. What makes moral blackmail special is that it leaves alternative courses of action looking morally unacceptable, in the eyes of the victim. 
For an act to count as one of moral blackmail, it must be exploitative, unjustified, malicious, unwarranted: in some respect it must be wrong. Nevertheless, moral blackmail can be an effective strategy for causing a person to do something, and sometimes, there is good reason for making a person perform a particular act, by any means available. Perhaps, for example, it is only by subjecting someone to moral blackmail that you can prevent some truly enormous harm. Perhaps you want to be relieved of the responsibility for taking your father to the hospital not because you want to take the day to yourself, but instead because you have been given a top secret mission on which depend the lives of thousands. Perhaps the best way for you to ensure that you can complete your mission without sacrificing your father is to subject your sister to moral blackmail.

While morally blackmailing your sister in such a case might be morally justified on the whole, it still involves your taking advantage of your sister; it is still exploitative and manipulative and, from your sister's point of view at least, unfair. So perhaps the right thing to say is that your act is wrong in some salient respect, and hence qualifies as an act of moral blackmail, even though it is morally justified all things considered.

The complication, in any event, arises equally for cases of ordinary blackmail. ${ }^{9}$ By threatening to release some embarrassing information about you unless you pay, I might secure the money I need to carry out my secret mission and save the lives of thousands. You are still mistreated, in such a case, and it would still be natural to say that you are subjected to blackmail, even if your being subjected to blackmail is worth it, given the wider context.

\footnotetext{
${ }^{9}$ See section 4 of C.A.J. Coady, 'The Problem of Dirty Hands,' The Stanford Encyclopedia of Philosophy (Spring 2014 Edition), Edward N. Zalta (ed.) [http://plato.stanford.edu/archives/spr2014/entries/dirty-hands/] Accessed 29 Dec 2015.
} 


\section{Moral blackmail in the family}

In the paper so far, I have tried to identify the phenomenon of moral blackmail and to explain what moral blackmail is and how it works. In closing the paper, I want to show that moral blackmail is a significant presence in everyday social life, by describing some of the ways in which it can influence moral relationships within the family. While moral blackmail can arise within all sorts of human interactions, there are several reasons to think that it has a special presence within families. ${ }^{10}$

For one thing, it is within families that we do much of the caring for the most vulnerable humans: the very young, the elderly, and the sick and infirm. One way to subject someone to moral blackmail is to manipulate her relationship with an innocent third party; that is a feature of all three of the cases of moral blackmail with which I began the paper. The family offers opportunities for exploiting relationships with the innocent and vulnerable.

For another thing, the family grounds many relationships that generate special moral reasons and obligations. Some of our moral obligations are owed to people generally, but others, it is plausible to think, are special obligations, held towards the particular individuals with whom we share intimate relationships; your obligations to a friend, for example, are different from your obligations to a stranger. ${ }^{11}$ Along with friendship, family relationships, like those between siblings, between parents and children, and between long-term partners, are often regarded as central cases of such morally powerful intimate relationships. Moral blackmail involves changing a

\footnotetext{
${ }^{10}$ In 'Moral Blackmail and Fiduciary Duties,' I explore some of the forms in which moral blackmail appears in employment negotiations and professional relationships. ${ }^{11}$ There is a large body of philosophical writing on the ethics of special relationships. For my own contribution and a summary of others' positions, see my Partiality (Princeton University Press, 2013).
} 
person's moral situation. If family relationships indeed generate special obligations, then the family offers special opportunities to change a person's moral situation; you can influence her moral reasons and obligations by influencing the needs and expectations of members of her family.

In addition, obligations within families are often shared, so that multiple parties are engaged in a collaborative project of looking after a family member. Parents share responsibilities for bringing up children, grown siblings share responsibilities for caring for elderly parents, and so on. Shared responsibilities create opportunities for moral blackmail, because by failing to do your part in meeting a shared responsibility, you can make the person with whom you share the responsibility morally obliged to meet it by herself. That is how you morally blackmail your sister, in the case in which you inform her that you will not be taking your father to the hospital after all.

Finally, relationships within the family tend to be long-lasting and open-ended and are often unchosen. You cannot choose your siblings or your parents. You can choose to have children but you cannot choose which children to have, or what needs your children will have, or what demands your children will make of you. It is not easy to end close family relationships; you cannot simply decide that you will no longer be someone's sibling, parent, or child, or that you will no longer be subject to the moral obligations that those relationships involve. As a result, we tend to be vulnerable within our family relationships. Our family relationships leave us with demanding obligations whose nature we cannot choose and that we are unable easily to dissolve. That vulnerability can be converted into vulnerability to moral blackmail. Where you cannot walk away from a set of obligations, it is easier for someone else to use those obligations to manipulate you. The fact that you cannot simply end your 
moral relationships with family members means that someone who can make those relationships more awkward or demanding thereby holds moral power over you.

Speaking generally, then, the family offers a moral environment ripe for moral blackmail. Here are a few of the more specific forms in which moral blackmail within the family tends to arise.

\section{Divorced parents}

Divorced parents are often especially able and motivated to subject each other to moral blackmail. Often, divorced parents, despite no longer sharing a romantic relationship, understand themselves to share an ongoing and important collaborative moral project: the project of looking after their children. Each parent may care deeply, and know that the other parent cares deeply, about giving the children a loving and stable upbringing, including rewarding relationships with both parents. Whether the children receive the upbringing that both parents are committed to providing will depend on such things as how far from each other the two parents live, whether the children are able to stay at a single school, how easy it is for the children to spend time with both parents, whether the children are able to maintain stable friendships, and whether the children are caught up in conflicts between the parents.

While pursuing their collaborative ethical project, divorced parents are likely to have divergent interests. They may have new partners, and perhaps new children. Their lifestyles and financial interests will no longer be entwined. Importantly, each parent may feel that she no longer has any special responsibility for helping the other parent lead a flourishing and rewarding life. Each parent is likely, indeed, to feel some resentment toward the other parent, perhaps including feelings of having been 
mistreated; the relationship between divorced parents may be collaborative as far as the project of raising children is concerned, but in other respects antagonistic.

As a divorced father, to give an example, you might have reasons, perhaps to do with your job or a new relationship, to live in a certain city. You might deliberately make an irrevocable commitment to living in that city, perhaps accepting a job or buying a house, knowing that once your commitment is made, it will be up to your ex-wife to live nearby; if she does not, then the children will be left unable to live near both their father and their mother, and without the stability that that arrangement would provide. You might see that this is an unfair burden to place on your ex-wife, and that it will reduce her quality of life and level of autonomy, but you might not care. You might be willing to leave your ex-wife forced to choose between doing what you want her to do and failing to do what will be best for her children.

As a divorced mother, you might take a job that leaves you free to see your children only at certain times, figuring that your ex-husband will rearrange his life to make sure that the children can see you when you are available. As great an inconvenience as your decision places upon your ex-husband, you might think that he deserves it, or that his convenience is not your concern anyway. You might deliberately leave your ex-husband with a choice between fitting in with the demands of your job and depriving his children of time with their mother.

Not all relationships between divorced parents meet this description, and some relationships between parents who are not divorced do meet it. I just mean to capture a combination of circumstances and motives that is often found between divorced parents. Another relationship within which the same basic dynamics are often found is that between grown siblings who do not get along, but who share a commitment to caring for their aging parents. In the case in which you blackmail your sister into 
taking your father to the hospital, you exploit her commitment to your shared duty towards your father and you display a lack of concern for her quality of life.

\section{Public policy and caring for the vulnerable}

We have special responsibilities to help meet the needs of our family members. What it takes to care for a family member depends not only on her needs, but also on what others to do help meet her needs. In particular, what it takes to look after a family member often depends on what resources are provided by the state. What you must do to meet the needs of a sick elderly parent, for example, will differ depending on whether or not you live under a state that provides care for people in your parent's condition; you will need to make greater sacrifices to secure your parent's best interests if you need to find and pay for her healthcare yourself. The same is true of looking after a disabled child, to give another example. A state that does more to provide care for children with disabilities reduces the moral burden carried by those children's families.

It is hence possible to conceive of some of our moral duties towards family members as duties to fill the gap left by other potential carers, including the state. The less the state provides, the more we are morally obliged to provide. That leaves the state able to take advantage of the structure of our duties.

Suppose that you are a policy maker, and one of your motives is to help make it the case that all citizens' basic material needs are met. You have no desire to leave elderly people or disabled children, for example, without the care they need. There are other calls upon your resources, however, and you need to decide what state resources will be devoted to providing healthcare and other kinds of support to needy citizens, and what resources will be allocated elsewhere. You may have the thought that if you 
direct fewer resources towards caring for needy citizens, then family members will make additional sacrifices to ensure that the care is provided anyway; the family members are morally obliged to provide that care when it is not provided by others. In light of that thought, you may decide to devote fewer resources to the care of needy citizens, aware that you thereby place an unfair burden upon families, but confident that the burden will be met.

Suppose that you face the decision of whether to provide funding for special transport needed by disabled students so they can participate in school camps and excursions. You might judge that if you do not fund the special transport, then the children's parents will pay for it themselves. Their alternative, once the state has failed to provide the funding, is to leave their children deprived of camps and excursions with their classmates. Failing to provide state funding for the special transport might be unfair, given the other burdens on the parents involved and given the responsibilities and resources of the state, but it might successfully move the moral obligation to provide the special transport onto the parents. The policy would then qualify as a piece of moral blackmail.

It seems to me that states, along with other institutions, are often able to avoid meeting their responsibilities to the needy by exploiting the special moral duties faced by family members. The structure of the moral duties at work can be complicated, in ways that make it easier for the state to make it look as though it is not doing anything wrong. It can be correctly said, after all, that people have a moral obligation to provide care for needy members of their families in such cases, so the state can say that it is simply leaving families to provide the care they are obliged to provide. It can be difficult to see that there is a separate question to be asked about whether families should have those particular moral obligations, and whether their being left with those 
obligations is a result of unjust decisions on the part of the state. It can be difficult for morally burdened families - doing their duty, but unjustly treated in being left with that duty - to find a way to express their legitimate complaints.

\section{Gender roles and moral blackmail}

In the paradigmatic cases of blackmail, whether an attempt at blackmail succeeds depends on whether the blackmailer is able to make a credible threat. When I attempt to get your money by threatening to release damaging information about you, I only stand a chance of getting the money if you believe that I really have the information and that I really am likely to release it. Moral blackmail, as noted earlier, does not always involve a threat, but still, the blackmailer often relies upon the victim's taking him seriously. When you send your sister the message saying that you will not be taking your father to the hospital, your attempt to influence her behavior will only succeed - she will only believe that she must take her father to the hospital if he is to get there at all - if she believes that you really are prepared to leave your father depending on her. If she suspects that you are bluffing, and that you will check in later and will indeed take your father to the hospital if necessary, then she is less likely to do what you want her to do.

In many societies, including Western societies, there is a traditional allocation of family responsibilities based on gender. In particular, women - as mothers, sisters, and daughters - are treated as holding the first responsibility for caring for the young, sick, disabled, and elderly. There is more pressure on mothers than on fathers to spend time with their children, and to sacrifice professional and other opportunities so as to care for children. Parents often assume that their daughters, more than their sons, will care for them in their old age. Men's contribution to the family is traditionally more 
likely to be conceived as that of bringing in money, as opposed to caring directly for needy family members. While allocations of family responsibilities according to gender are increasingly recognized as unjust, they persist, and they have consequences for the moral relationships between men and women within the family.

One consequence of the traditional division of responsibilities is that women, much more than men, are judged morally based on how much care they give to their children, siblings, and parents. These moral judgments come from other family members, from peers, and from society at large; for example, there is greater bite to the accusation of being a neglectful mother than of being a neglectful father. Another consequence is that women, as compared to men, are likely to feel greater moral responsibility for caring for vulnerable family members. Women are more likely to feel guilty about leaving the care of needy family members to others, and more likely to judge themselves based on how much care they provide within the family.

The differences between women's and men's expectations, of themselves and of others, makes a difference to what women and men respectively can credibly threaten and can credibly claim to intend. Think again about the case in which you try to force your sister to take your father to the hospital. If you are a man telling your sister that you will not be keeping your promise to take your father to the hospital, then it may well be easy for your sister to believe you, and she may well feel more pressure to change her plans and take your father to the hospital herself. It may be known by both of you that the moral stakes, so to speak, are higher for her than for you. If your father does not get the medical care he needs, the moral judgment that falls on her will be harsher than the moral judgment that falls on you.

Conversely, if we change the case and imagine that you are a daughter, and you are leaving a message for your brother to say that you will not be taking your 
father to the hospital, it may well be less likely that your brother will take you seriously. Knowing what you both know about the different moral expectations faced by the two of you, based on your different genders, your brother may correctly think it very unlikely that you would leave him with the sole responsibility for taking your father to the hospital. He may be more inclined to judge that you are bluffing; you may fully expect that he will be inclined to judge that you are bluffing; and so you may be unable to place the moral burden on him with confidence that he will meet it.

Where women are taken to have greater responsibilities for caring within the family, women are more vulnerable to being manipulated by way of their moral sensibilities. One of the forms of exploitation that women often face as a result of traditional cultural conceptions of gender roles within the family is a distinctive form of moral exploitation: the exploitation involved in moral blackmail.

\section{Conclusion}

It is possible to force someone to do something by making her alternatives morally unacceptable. Often, so forcing someone to do something is a way of wrongfully exploiting her. This is the form of wrongful manipulation that I have called "moral blackmail." Moral blackmail, I have tried to show, is like ordinary blackmail, insofar as it employs the same basic strategy of manipulation, but it is also different from ordinary blackmail in significant respects. Most importantly, to understand moral blackmail we need to understand how morality can be, as I have put it, turned against itself. On the view I have offered, moral blackmail works by changing the victim's moral situation. The moral blackmailer wrongfully leaves his victim with certain (genuine!) moral obligations; he wrongfully makes it the case that 
it would be wrong for the victim to do anything other than what the blackmailer wants her to do.

While moral blackmail, so described, is a complex notion and seems to require quite careful and conscious strategizing, the more you look for moral blackmail the more moral blackmail you find. Moral blackmail turns out to be a familiar presence in many kinds of human interactions, especially those that involve special responsibilities for caring for others.

I have not said anything much about how moral blackmail should be assessed, used, and guarded against. I think we can draw a couple of overall morals, however.

First, the discussion of moral blackmail shows that the fact that you are morally required to do something does not imply that you should be morally required to do it, or that you have no legitimate complaint about being morally required to do it. It is possible coherently to complain that you should not have a certain moral obligation, without denying that you in fact have that obligation.

Second, the discussion of moral blackmail shows that there is a special moral vulnerability involved in taking on certain moral obligations, especially obligations that involve caring for others. Among the costs of assigning certain roles within the family, for example, is a kind of moral cost: the cost of being vulnerable to moral blackmail. That cost should fairly be considered when assessing the justice of the caring arrangements concerned. Speaking generally, when we ask whether it is fair that certain people have certain responsibilities, one question we should ask is, "To what extent and in what ways does their having those responsibilities leave them open to moral blackmail?" 12

${ }^{12}$ I am grateful for helpful comments from two anonymous referees, and from Samantha Brennan, Ramon Das, Nicky Drake, Charles Jones, Don Locke, Michael Gilchrist, Alice MacLachlan, Carolyn McLeod, and Justin Sytsma. 